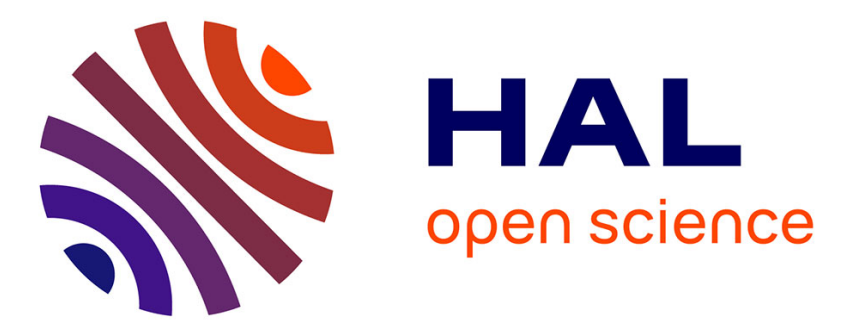

\title{
The hydration features of carbohydrate determinants of Lewis antigens
}

Michael Reynolds, Andreas Fuchs, Thisbe Kirsten Lindhorst, Serge Perez

\section{To cite this version:}

Michael Reynolds, Andreas Fuchs, Thisbe Kirsten Lindhorst, Serge Perez. The hydration features of carbohydrate determinants of Lewis antigens. Molecular Simulation, 2008, 34 (04), pp.447-460. 10.1080/08927020701713878 . hal-00515020

\section{HAL Id: hal-00515020 \\ https://hal.science/hal-00515020}

Submitted on 4 Sep 2010

HAL is a multi-disciplinary open access archive for the deposit and dissemination of scientific research documents, whether they are published or not. The documents may come from teaching and research institutions in France or abroad, or from public or private research centers.
L'archive ouverte pluridisciplinaire HAL, est destinée au dépôt et à la diffusion de documents scientifiques de niveau recherche, publiés ou non, émanant des établissements d'enseignement et de recherche français ou étrangers, des laboratoires publics ou privés. 


\section{Molecular Simulation \\ Journal of \\ Experimental Nanoscience \\ $\because$ Taylor \& Francis \\ Taglor \& Francis Group}

\section{The hydration features of carbohydrate determinants of Lewis antigens}

\begin{tabular}{|c|c|}
\hline Journal: & Molecular Simulation/Journal of Experimental Nanoscience \\
\hline Manuscript ID: & GMOS-2007-0084.R1 \\
\hline Journal: & Molecular Simulation \\
\hline $\begin{array}{r}\text { Date Submitted by the } \\
\text { Author: }\end{array}$ & 27-Sep-2007 \\
\hline Complete List of Authors: & $\begin{array}{l}\text { Reynolds, Michael; CERMAV-CNRS, Glycobiologie Moleculaire } \\
\text { Fuchs, Andreas; Christiana Albertina University of Kiel, Otto Diels } \\
\text { Institute of Organic Chemistry } \\
\text { Lindhorst, Thisbe; Christiana Albertina University of Kiel, Otto Diels } \\
\text { Institute of Organic Chemistry } \\
\text { Perez, Serge; CERMAV-CNRS, Glycobiologie Moleculaire }\end{array}$ \\
\hline Keywords: & Lewis $X$ trisaccharide, Lewis $Y$ tetrasaccharide, Molecular dynamics \\
\hline
\end{tabular}




\title{
The hydration features of carbohydrate determinants of Lewis antigens
}

\author{
M. REYNOLDS $\dagger$, A. FUCHS $\ddagger, T$. K. LINDHORST $\ddagger$ and S. PEREZ $\dagger *$ \\ † CERMAV-CNRS, BP 53-38041 Grenoble, France; \\ \$ Otto Diels Institute of Organic Chemistry, Christiana Albertina University of Kiel, \\ Otto-Hahn-Platz 4, 24098 Kiel, Germany.
}

The hydration behaviour of two Lewis carbohydrate determinants, Lewis $\mathrm{X}\left(\mathrm{Le}^{\mathrm{x}}\right)$ (1a) and Lewis $\mathrm{Y}\left(\mathrm{Le}^{\mathrm{y}}\right)$ (1b), have been investigated by a comparative $20 \mathrm{~ns}$ molecular dynamics (MD) study. The detailed hydration of the two oligosaccharides was described using the AMBER-based GLYCAM04 force field which is developed specifically for modelling carbohydrates.

In comparison with previous in vacuo MD simulations and high resolution NMR studies, the solvated structures have shown to be dynamically stable and equally rigid with regards to glycosidic linkage torsion angles. Comparisons have also been made between the solvated structures and crystal structures currently available, namely the $\mathrm{Le}^{\mathrm{x}}$ dimer crystal, the crystal structure of $\mathrm{Le}^{\mathrm{x}}$ complex with the 291-2G3-A-Fab antibody; and the crystal structures of Le $\mathrm{e}^{\mathrm{y}}$ complexed with the hu3S193 and CBR96 antibodies. When the solvated structures and respective crystal structures were overlaid for comparison the only significant difference was the Galp(3)-O5-C5-C6-O6 and the GlcpNAc(2)-O5-C5-O6-C6 orientations.

The hydration sphere was investigated using a radial pair distribution function. Several solute heteroatoms were identified for the occurrence of bridging events where a solute heteroatom is linked to (at least) one other via a solvent molecule. 
Keywords: Lewis X trisaccharide, Lewis Y tetrasaccharide, molecular dynamics

\section{Introduction}

The sequential addition of L-fucose monosaccharides onto oligosaccharide precursor chains of glycolipids or glycoproteins results in the formation of the so-called Lewis (Le) carbohydrate determinants that can be classified as type $1\left(\mathrm{Le}^{\mathrm{a}}\right.$ and $\left.\mathrm{Le}^{\mathrm{b}}\right)$ and type 2 $\left(\mathrm{Le}^{\mathrm{x}}\right.$ and $\left.\mathrm{Le}^{\mathrm{y}}\right)$ antigens. The incorporation of $\mathrm{Le}^{\mathrm{a}}$ and $\mathrm{Le}^{\mathrm{b}}$ determinants into erythrocyte membranes creates the blood-group antigens. Other structurally related determinants, i.e. $\mathrm{Le}^{\mathrm{x}}$ and $\mathrm{Le}^{\mathrm{y}}$ (Fig. 1) are expressed in only a few cell types such as certain epithelial cells. Lewis antigens have been found to be expressed at high density in many carcinomas.[1] $\mathrm{Le}^{\mathrm{x}}$ and $\mathrm{Le}^{\mathrm{y}}$ antigens are considered to be tumour-associated antigens and they represent targets for immunotherapeutic strategies for carcinoma.[2] The threedimensional structures of these carbohydrate determinants of free Lewis system antigens and their complexes with antibodies have been extensively studied.[2] The rigid nature of Lewis determinants is fairly well established. Consequently, their free conformation is likely to represent the bio-active conformation, i.e. the one recognised by a protein.[2] This is true for Lewis determinants bound to antibodies specific for type 2 determinants. The rigid conformation of $\mathrm{Le}^{\mathrm{y}}$, when presented to the immune system on tumour cells, has been shown to elicit a structurally conserved antibody response.[3] The availability of well resolved 3D structures of proteins interacting with Lewis antigens enlightens the role of ordered water molecules in antibody recognition. Although water molecules have a fundamental role in carbohydrate-protein interactions and carbohydrate recognition, the biological importance of this aspect of intermolecular recognition in aqueous phase as well as the complexity of its molecular dynamics is not fully understood. 
The aim of our investigation was to study the solvated structures of the type 2 Lewis determinants using computer modelling and comparing the results with the structures found in crystal structures and complexes with antibodies. Molecular dynamics (MD) studies were carried out in order to monitor the hydration sphere of the tri and tetrasaccharide, and in particular, to study water molecule residence times and bridging events. The bridging events, which temporarily link one saccharide heteroatom to (at least) one other saccharide heteroatom via a connecting water molecule, are thought to have a great importance in the 3D structure of the saccharides which in turn leads to its biological activity in living organisms. To investigate the solvated structures further, we have made comparisons between the MD results and crystal structures in order to find "common" bridging water molecules i.e. bridging water molecules which are not displaced upon interaction with a receptor. Other heteroatoms, for example those found in amino acid residues, which may displace bridging water molecules from the solute have also been identified. The loss of ordered water from the solvated systems would contribute to an increase in entropy of the system as it is being expelled from an ordered position to the disordered bulk. By contrast, water molecules which are found to remain "complexed" to the solute upon interaction would not be contributing to the change in entropy and so therefore must be contributing to the affinity between the solute and its receptor.

\section{Materials and methods}

\subsection{Nomenclature}

Lewis $\mathrm{X}$ trisaccharide $\left(\mathrm{Le}^{\mathrm{x}}\right)$ [ $\beta$-D-Gal $p-(1-4)[\alpha-\mathrm{L}-$ Fuc $p-(1-3)]-\beta-\mathrm{D}-\mathrm{Glc} p$ NAc] (Fig. 1a) Lewis $\mathrm{Y}$ tetrasaccharide $\left(\mathrm{Le}^{\mathrm{y}}\right)$ [ $\alpha$-L-Fuc $p-(1-2)-\beta-\mathrm{D}-\mathrm{Gal} p-(1-4)[\alpha-\mathrm{L}-\mathrm{Fuc} p-(1-3)]-\beta-\mathrm{D}-$ Glc $p$ NAc] (Fig. 1b) 
[Figure 1 here]

All glycosidic linkages are described by the standard nomenclature of $\Phi$ and $\Psi$ where $\Phi$ $=\mathrm{O} 5-\mathrm{C} 1-\mathrm{Ox}-\mathrm{Cx}$, outlined in red in figure 1 , and $\Psi=\mathrm{C} 1-\mathrm{Ox}-\mathrm{Cx}-\mathrm{C}(\mathrm{x}+1)$, outlined in blue in figure 1.

Conformational flexibility around the glycosidic linkage of $\operatorname{Le}^{\mathrm{x}}$ between Fucp(1) Glc $p$ NAc(2) is described by the two torsion angles: $\Phi=$ O5-C1-O3' $-\mathrm{C} 3$ ' and $\Psi=\mathrm{C} 1-$ O3'-C3'-C4'. In the case of the Gal $p(3)-\operatorname{Glc} p N A c(2)$ linkage, the torsion angles are defined as: $\Phi=\mathrm{O} 5 "-\mathrm{C} 1 "-\mathrm{O} 4 '-\mathrm{C} 4$ ' and $\Psi=\mathrm{C} 1{ }^{\prime}-\mathrm{O} 4{ }^{\prime}-\mathrm{C} 4 '-\mathrm{C} 5$ '.

For Le $\mathrm{y}^{\mathrm{y}}$, the glycosidic linkages of Fucp(1) - Glc $p \mathrm{NAc}(2)$ and Gal $p(3)-\operatorname{Glc} p \mathrm{NAc}(2)$ are defined as above for $\operatorname{Le}^{\mathrm{x}}$. The torsion angle of the Fucp(4) - Galp(3) linkage is defined as $\Phi=\mathrm{O} 5 ",-\mathrm{C} 1 "=-\mathrm{O} 2 "-\mathrm{C} 2 "$ and $\Psi=\mathrm{C} 1 ",-\mathrm{O} 2 "-\mathrm{C} 2 "-\mathrm{C} 3 "$.

The orientation of the hydroxy methyl groups is given by torsion angle $\omega$ (outlined in green in figure 1) (O5"-C5"-C6"-O6") and the gauche/trans conformers are denoted by the standard notation $\boldsymbol{g g}, \boldsymbol{g t}$, $\mathbf{t g}$, which corresponds to angles of $-60^{\circ}, 60^{\circ}$ and $180^{\circ}$ respectively. The sign of the torsion angles is defined in agreement with the IUPAC Commission of Biochemical Nomenclature.[4]

\subsection{Molecular dynamics simulations}

2.2.1 Constant nTP molecular dynamics using AMBER.

Simulations were conducted using the AMBER software package together with the GLYCAM04 force field parameters, which is specifically designed for http://mc.manuscriptcentral.com/tandf/jenmol 
carbohydrates.[5] The solution behaviour of the trisaccharide $\mathrm{Le}^{\mathrm{x}}$ and the tetrasaccharide $\mathrm{Le}^{\mathrm{y}}$ was investigated by calculating a 20 ns constant nTP MD trajectory with explicit water molecules for each saccharide. To model the water molecules, the TIP3 energy function was applied.[6] All hydrogen atoms were explicitly included in the simulation however all bond lengths, including hydrogen, were constrained using the SHAKE algorithm.[7] This allowed for an integration time step of 2 fs within the MD simulation. The periodic box was prepared by solvation of the crystal structures with 503 and 517 TIP3 water molecules for $\mathrm{Le}^{\mathrm{x}}$ and $\mathrm{Le}^{\mathrm{y}}$ respectively. This was done using the Xleap module supplied with the AMBER package to give a concentration of $5.7 \%(\mathrm{w} / \mathrm{w})$ for $\mathrm{Le}^{\mathrm{x}}$ and $6.9 \%(\mathrm{w} / \mathrm{w})$ for $\mathrm{Le}^{\mathrm{y}}$. Initial coordinates for $\mathrm{Le}^{\mathrm{x}}$ and $\mathrm{Le}^{\mathrm{y}}$ were taken from a crystal structure,[8] and extraction from an antibody complex respectively.[9] A non-bonded interactions cut-off value of $8 \AA$ was applied during the whole simulation. The solvated systems were energy minimised with 50 steps of steepest descent followed by 10000 iterations of conjugate gradient minimisation in order to relax steric conflicts during the artificial solvation process. After 10 ps of constant $\mathrm{nVT}$ MD simulation at $300 \mathrm{~K}$, with initially assigned velocities from a Boltzman distribution at the same temperature, the systems were equilibrated during a total of $8.5 \mathrm{~ns} \mathrm{MD}$ trajectories under constant nPT conditions also at $300 \mathrm{~K}$. After equilibration, ten $2 \mathrm{~ns}$ trajectories of production gave a total of $20 \mathrm{~ns}$ for both saccharides. Coordinate sets were saved every 50 steps $(0.1 \mathrm{ps})$ for subsequent analysis.

\section{Results and discussion}

\subsection{Solute Conformation from Solvated MD Simulations}

\subsubsection{Solute conformation.}

As mentioned in the introduction, due to the rigidity of the Lewis determinants, it is 
proposed that their conformations calculated from in vacuo MD simulations is the most biologically active. If this is true, then we should find that the conformations of the Lewis structures, and their rigid natures, do not change when placed in solution. From our MD simulation in solution, we indeed find that the structures of both $\mathrm{Le}^{\mathrm{x}}$ and $\mathrm{Le}^{\mathrm{y}}$ remain rigid throughout the entire simulation time. The mean distance between Galp(3)$\mathrm{C} 1$ and Fucp(1)-C1 in both $\mathrm{Le}^{\mathrm{x}}$ and $\mathrm{Le}^{\mathrm{y}}$ has been calculated as $4.7 \pm 0.1 \AA$ and the distance between Galp(3)-C4 and Fucp(1)-C4 is calculated to be $4.9 \pm 0.3 \AA$ and $4.8 \pm$ $0.3 \AA$ for $\mathrm{Le}^{\mathrm{x}}$ and $\mathrm{Le}^{\mathrm{y}}$ respectively.

Figure 2 shows the potential energy surfaces for all of the glycosidic linkages of the solvated $\mathrm{Le}^{\mathrm{x}}$ and $\mathrm{Le}^{\mathrm{y}}$ molecules in terms of $(\Phi, \Psi)$-space. If several minima in Figure 2 had been seen, this would be evidence suggesting several solute conformations (and thus several torsion angles for each linkage) were accessible under the simulation conditions. However, in our study this is not the case, only one minimum is seen for each glycosidic linkage thus showing only one stable and accessible conformation where only subtle changes in the glycosidic linkage torsion angles are observed.

Figure 3, which shows the variation of each torsion angle with respect to time throughout the simulation, also confirms this rigid nature. For all glycosidic torsion angles, only small angle variations about a mean value are observed. If several conformations were accessible, one would expect to see a larger variation in the relevant torsion angles. An example of this would be a more exaggerated case than that seen for Galp(3)-Fucp(4) glycosidic linkage, where a different angle for $\Phi$ and $\Psi$ would be occupied for longer time durations.

[Figure 2 here] 
[Figure 3 here]

\subsubsection{Hydroxyl group orientation at Galp(3)-O6.}

The orientation of the primary hydroxyl group of Galp(3) was investigated by calculating the torsion angle defined by $\omega$ and monitoring the amount of time each rotomer was adopted. Figure 4 shows the histograms of the MD trajectories for the 20 ns simulations of the tri and tetrasaccharides, and shows the distribution of the torsion angles adopted.

[Figure 4 here]

In both $\mathrm{Le}^{\mathrm{x}}$ and $\mathrm{Le}^{\mathrm{y}}$, all of the rotomers are seen, however, in both cases a $\boldsymbol{g t}$ conformation is occupied most of the time by the primary hydroxy group which is in accordance with the stereoelectronic 'gauche' effect. The ratio of $\boldsymbol{g} \boldsymbol{g}: \boldsymbol{g} \boldsymbol{t}: \boldsymbol{t} \boldsymbol{g}$ for $\mathrm{Le}^{\mathrm{x}}$ and $\mathrm{Le}^{\mathrm{y}}$ is observed to be $2.8 \%: 85.4 \%: 11.8 \%$ and $7.3 \%: 80.1 \%: 12.6 \%$ respectively. A study by Serianni et al investigated the conformation of methylated ${ }^{13} \mathrm{C}$ labelled $\beta$-DGal $p$ in $\mathrm{D}_{2} \mathrm{O}$ solution using ${ }^{1} \mathrm{H}$ NMR. They found that for the $1-$ methyl- $\beta$-D- $\left[1-{ }^{13} \mathrm{C}\right] \mathrm{Gal} p$ monomer, the distribution of conformers was $\sim 0 \%: 73 \%: \sim 25 \%$ thus the monomer adopting a $\boldsymbol{g} \boldsymbol{t}$ conformation most of the time, thus confirming our own results.[10] The gt conformation exhibited by galactopyranosides has long been thought to have arisen from the effects of solvent interactions.[11] Comparing the distribution of conformations in $\mathrm{Le}^{\mathrm{x}}, \mathrm{Le}^{\mathrm{y}}$ and the NMR results for the $\beta$-D-Gal $p$ monomer, the presence of the Fucp(1)-GlcpNAc(2) moiety has a slight effect on the conformation of the primary hydroxyl group at Galp(3)-O6. This causes a reduction in the popularity of the $\boldsymbol{t g}$ conformation and increases the population in the $\boldsymbol{g t}$ and $\boldsymbol{g g}$ conformations. The Fucp(1)-GlcpNAc(2) moieties, having a rigid nature, could exhibit a directing effect on the Galp(3) unit by either increasing the stability of the $\boldsymbol{g g}$ conformation or decreasing 
the stability of the $\boldsymbol{t g}$ conformation in an aqueous solution. This could occur via Fucp(1)-GlcpNAc(2), providing steric bulk around Galp(3)-C6 or by inducing a disturbance in the solvation sphere surrounding the area thus causing hydrogen bonds to occur at different locations and / or geometries. In the Galp monomer, it is the 1-3 diaxial interaction between $\mathrm{Gal} p-\mathrm{O} 4$ and Galp-O6 that causes the destabilisation in the gg conformation.[12] With the introduction of the Fucp(1)-GlcpNAc(2) moieties, the oxygen at the Galp(3)-O4 position may also be interacting with the Fucp(1)-HC2 position thus providing a slight stabilising effect on the $g \boldsymbol{g}$ conformation. The small increase in the population of the $g t$ conformation could simply be due to a change in the hydration sphere surrounding the Gal $p(3)$ ring. The presence of Fucp(4) in $\mathrm{Le}^{\mathrm{y}}$ seems to induce an effect of its own as the gt conformation is slightly less favoured in comparison with $\mathrm{Le}^{\mathrm{x}}$. This, again, is most likely due to a difference in hydration spheres as steric hindrance is unlikely to occur from the Fucp(4) moiety as it is situated at the opposite side of the pyranose ring.

\subsection{Behaviour in Solution}

\subsubsection{Influence of water}

It has long been known that water molecules induce effects on the conformational behaviour of biologically important molecules. In particular, they have been described as "chaperone" molecules involved in organising, in our case the protein and the saccharide molecules, into active conformations.[13] It is also well known that even small changes in molecular composition can induce large effects on the hydration sphere and hence lead to different conformations and even different biological properties and functions. There are several examples in the literature where, upon glycosylation, the properties of the acceptor are dramatically altered.[14-17] One particular example of this can be seen in the work of Avenosa et. al. and their studies on the glycosylation of Serine and Threonine.[18] They report that a small difference in amino acid structure induces large changes in saccharide-amino acid torsion angle and hydration sphere leading to rather different saccharide-amino acid conformations (and 
thus oligosaccharide presentation), different water-structuring abilities and in turn induce a large difference in biological function (antifreeze activity being the most prominent feature).

It should also be pointed out that within the studies of Avenosa et. al. and Wong et. al, that although the saccharide-amino acid torsion angles changed dramatically, the conformation of the saccharides did not.[15, 18, 19] As our studies were concerned only with the saccharides, and the variety and complexity of the system increases dramatically when considering glycosylated biomolecules, we have used saccharides methylated at the anomeric position of the GlcpNAc residue. This is the position that the saccharides would be conjugated to other biomolecules, and by using only a methyl group we would be able to study a somewhat "generic" behaviour (if one exists!) of cases where the saccharides are conjugated to other biomolecules to form the Lewis and sialyl-Lewis determinants of glycolipids and glycoproteins.

Nevertheless, it should still be pointed out that in order for one to study more exactly the true behaviour of a glycosylated biomolecule, one must consider at least some portion of the biomolecule to which the saccharide is conjugated as well as the behaviour and influence of the first hydration shell on structural reorganisation.

\subsubsection{Diffusion behaviour.}

Following the Einstein relation,[20,21] the translational coefficient was estimated by calculating the mean square displacement auto correlation function at the centre of mass of the solute molecule as a function of $\Delta t$. This equation is valid for long times however the function is only calculated up to $\Delta t=20 \mathrm{ps}$ as the statistical significance decreases rapidly. Figure 5 shows the translational diffusion coefficient for the solute molecules and that asymptotic behaviour (i.e. random translational diffusion) is reached by the end of $20 \mathrm{ps}$. Thus, the molecule has no memory of its initial translational motion.

\subsubsection{Rotational diffusion.}

The rotational diffusion time was estimated by monitoring the dipole moment vector as a function of time.[21] The rotational diffusion can be roughly determined by the time 
when the average angular displacement becomes uncorrelated (orthogonal).[22] Figure $5 \mathrm{~b}$ shows the rotational diffusion of both $\mathrm{Le}^{\mathrm{x}}$ and $\mathrm{Le}^{\mathrm{y}}$ and that random rotational behaviour can be observed after $1 \mathrm{~ns}$.

[Figure 5 here]

\subsubsection{Radial pair distributions.}

Radial pair distribution functions, rdf, $g(r)$, were calculated between selected atoms of the saccharides and all of the water molecules in order to characterise the overall solvation of $\mathrm{Le}^{\mathrm{x}}$ and $\mathrm{Le}^{\mathrm{y}}$.[22] The distribution function gives the probability of finding a water molecule at a given distance $r$ from the specified saccharide heteroatom, relative to the probability expected for a random distribution at the same distance. This is to say, the random distribution of water molecules in the bulk solution will have a constant density where as the density of the water molecules close to the saccharide molecules will vary depending on the solute-solvent interactions. Hydrophobic regions of the solute molecule will induce a reduction in the solvent density where as the contrary will be true for hydrophilic regions of the saccharide molecules. The first sphere of nearest neighbours is indicated by a maximum in $g(r)$ at $2.8 \AA$ and the limitations of the first sphere are indicated by a minimum in $g(r)$ at $3.5 \AA$ (Fig. 6).[22] The radial distributions were obtained using the ptraj tool supplied with the AMBER program package. The number of nearest neighbour water molecules, calculated as a function of time, for Le ${ }^{\mathrm{x}}$ was found to be 9.9 and 40.1 at 2.8 and $3.5 \AA$ respectively. Hydration numbers for Le $^{\mathrm{y}}$ were calculated as 12.1 and 44.8 respectively.

[Figure 6 here]

\subsubsection{Anisotropic hydration}


The next step was to investigate the anisotropic hydration of the solute. Since radial pair distribution functions only carry hidden information on localised hydration sites, normalised two-dimensional radial pair distributions[23] were calculated for all possible shared water density sites (Os1...Ow... Os2) where Ow is the water oxygen and Os the solute oxygen. In these calculations, the likelihood of finding a water molecule in a well-defined local intersection area is compared and scaled to the likelihood of finding a bulk water molecule in the same local intersection area. Such calculations lead to water densities higher than bulk water density when structural or semi-structural water molecules are present. Table 1 shows the peak density of the most important interglycosidic water bridges found in the trajectories.

\section{[Table 1 here]}

In general, a "normal" profile for exposed hydroxy groups is observed. However, reduced hydration for inner oxygen atoms is visible, especially for the glycosidic linkages and in fact the GlcpNAc(2)-O3 in $\mathrm{Le}^{\mathrm{y}}$ has no first hydration shell. In terms of solvent density, reduced hydration is visible for Galp(3)-O4 in $\mathrm{Le}^{\mathrm{x}}$ and $\mathrm{Le}^{\mathrm{y}}$ due to shielding from the fucose residue.

For the $1 \mathrm{D}$ rdf of $\mathrm{Le}^{\mathrm{y}}$, the oxygen atoms in the locations of Galp(3)-OH3 and Fucp(4)$\mathrm{OH} 2$ have small and negative $\Delta \delta$ of $-0.1 \mathrm{ppm}$. The relative maximum density in the rdf is not reduced in comparison with the solvent exposed hydroxyl groups. This could indicate that there is no steric hindrance of solvation compared with the shielded oxygen atoms such as Galp(3)-O4 and the glycosidic oxygen atoms.

\subsubsection{Radial hydration.}


The calculation of the 2D radial pair distribution functions is performed in an analogous method to the 1D distribution function,[23] but with respect to two specific solute atoms,[24] and were obtained using the Fortan programs previously published.[22] Figure 7 shows the 2D distribution functions for selected heteroatoms of $\mathrm{Le}^{\mathrm{x}}$ and $\mathrm{Le}^{\mathrm{y}}$. The 2D rdfs are, in general, identical for both saccharides. However, there is an exception for the saccharide atoms close to the additional fucose residue in $\mathrm{Le}^{\mathrm{y}}$. The $2 \mathrm{D}$ cross peak for Galp(3)-O3 - Fucp(4)-O2 (Fig. 7f) shows a bridging event which is occupied for $19.2 \%$ of the simulation time. The average residence time for a water molecule interacting with Galp(3)-O3 is 0.32 ps longer in $\mathrm{Le}^{\mathrm{y}}$ than that in $\mathrm{Le}^{\mathrm{x}}$ (Table 1). This indicates that the additional 0.32 ps residence per water molecule is due solely to the presence of the Fucp(4) residue.

[Figure 7 here]

The radial distribution of water molecules between Gal $p(3)-\mathrm{O} 2$ and Glc $p$ NAc(2)-O6 (Fig. 7a) shows that the heteroatom - water interactions are independent of each other i.e. the same water molecule is never interacting with both heteroatoms at the same time. The radial distribution between Fucp(1)-O3 and Fucp(1)-O4 shows a small increase in "shared" solvent density between the heteroatoms but this is not indicative of a dedicated shared solvent molecule interaction. It is possible that this region represents a transition state position where one solvent molecule resides between individual interactions with the heteroatoms $(\mathrm{Os} 1 \ldots$ Ow $\rightarrow$ Os1... Ow..... Os $\rightarrow$ Os1..... Ow...Os2 $\rightarrow$ Ow... Os2). The other heteroatom radial distribution functions (Galp(3)-O6 and Fucp(1)-O2 of $\mathrm{Le}^{\mathrm{x}}$ and $\mathrm{Le}^{\mathrm{y}}$ and also Fucp(4)-O2 and Galp(3)-O3 in $\mathrm{Le}^{\mathrm{y}}$ ) have symmetrical hydration patterns indicating a strong interaction with a shared water molecule between the two heteroatoms. The minimum corresponds to the equilibrium distance between the heteroatoms where the water molecule resides 
(Os1...Ow ...Os2).

\subsubsection{Residential behaviour of water molecules and bridging significance.}

Residence times for individual selected saccharide oxygen atoms were obtained by analysing their trajectory, on a frame by frame basis,[22] counting all water molecules which entered the first hydration shell (as defined by the minimum in the individual radial distribution function). Bridging times and significance for selected intramolecular hydrogen bonds mediated by single water molecules (structural water molecules) were calculated by identifying solvent molecules (represented by their oxygen atom) closer than $3.5 \AA$ to the corresponding sugar atoms.

Maximum and average residence times are calculated for the corresponding (water) oxygen atoms at a distance of less than $3.5 \AA$ (Table 1 ). It can be seen that in the case of $\mathrm{Le}^{\mathrm{x}}$, the oxygen atoms at the positions of Fucp(1)-O2 and Galp(3)-O2 have the longest maximum $\mathrm{H}_{2} \mathrm{O}$ residence times. This would correspond to points on the molecular surface of the molecule which are the most hydrophilic and least sterically hindered and thus easily accessible by solvent molecules. Assuming that the stronger solute-solvent interactions have longer residence times, and by comparing the maximum and average residence times, these two sites can be shown to experience a multitude of interactions of varying strengths. For the Fucp(1)-O2 this could be explained by the occurrence of bridging interactions. Most Fucp(1)-O2 $-\mathrm{OH}_{2}$ interactions are relatively weak, leading to short residence times. This could be due to the solute interacting solely with the hydroxyl group at Fucp(1)-O2, thus giving rise to a two-body interaction (Os...Ow). However, as shown in figure $7 \mathrm{~b}$, the solvent molecule is known to interact with at least one other solute oxygen atom (at the Galp(3)-O6 and potentially also at the Fucp(1)-O3) position. Obviously, the more interactions experienced by the solvent molecule at the 
same time (i.e. one water molecule interacting with more than one oligosaccharide heteroatom), the stronger the solute-solvent interaction will be and hence a longer maximum residence time will be observed.

In most cases, the average residence time $\left(\mathrm{T}_{\mathrm{av}}\right)$ for $\mathrm{Le}^{\mathrm{y}}$ is almost identical to that of $\mathrm{Le}^{\mathrm{x}}$. The value of $\mathrm{T}_{\mathrm{av}}$ for $\mathrm{Le}^{\mathrm{x}}$ is, on average 0.02 ps longer. However, the maximum residence times $\left(\mathrm{T}_{\max }\right)$ of $\mathrm{Le}^{\mathrm{x}}$ and $\mathrm{Le}^{\mathrm{y}}$ can be seen to have a greater variation in comparison with each other. The $\mathrm{T}_{\max }$ of $\mathrm{Le}^{\mathrm{x}}$ being, on average, 0.4 ps longer. The oxygen at the Galp(3)-O2 is excluded from this comparison as obviously, this environment changes greatly due to the glycosidic bond to the additional Fucp(4) residue in $\mathrm{Le}^{\mathrm{y}}$. Some heteroatoms do seem to have different properties in the two molecules, in particular the Fucp(1)-O2, GlcpNAc(2)-O6 and Glc $p$ NAc(2)-N positions. It is clear that the addition of the Fucp(4) residue is the soul cause for the difference in hydration pattern. As seen in Fig. 3, the glycosidic bond between Gal $p(3)$ and Fucp(4) is more flexible than the other linkages of $\mathrm{Le}^{\mathrm{x}}$ and $\mathrm{Le}^{\mathrm{y}}$ and it is perhaps this increase in flexibility which exerts steric hindrance and / or induces a disturbance on the hydration shell.

\subsubsection{NMR results.}

The chemical shifts of the hydroxy protons of oligosaccharides vary depending on interactions with solvent molecules. It is for this reason that they can be used as probes for conformational analysis. Reduced hydration due to steric hindrance, or interaction with acetal oxygen atoms, leads to a negative value of $\Delta \delta\left(\Delta \delta=\delta_{\text {Oligosaccharide }}-\right.$ $\delta_{\text {Monosaccharide }}$ ) where as a positive value of $\Delta \delta$ indicates that the hydroxy proton is deshielded due to being in close proximity to, and interacting with, other hydroxyl groups.[25] 
In the case of $\mathrm{Le}^{\mathrm{x}}$, there is a negative value of $\Delta \delta$ for $\mathrm{Fuc} p(1)-\mathrm{OH} 2$ and a positive value for the $\Delta \delta$ of Fucp(1)-OH3. However, this is not shown in the MD simulation as the simulation suggests that the $\Delta \delta$ for both positions are identical. The complex structural hydration pattern of $\mathrm{Le}^{\mathrm{x}}$ is not likely to be due to steric hindrance from the acetamido group of $\mathrm{GlcpNAc}(2)$ as the mean distance between the $\mathrm{CO}$ and $\mathrm{Fucp}(1)-\mathrm{OH} 2$ is $4.0+/-$ $0.8 \AA$ and during only $3.5 \%$ of the simulation time is that distance equal to, or closer than, the H-bonding distance of $1.9 \AA$. In the 2D cross peaks for Fucp(1)-O2 with GlcpNAc(2)-CO (Fig. 7e) there is a strong bridging interaction which, for the duration of the simulation, was populated for $34.2 \%$ of the time. There is also a strong bridging interaction between Fucp(1)-O2 and Galp(3)-O6 (Fig. 7b) which is occupied for $35.4 \%$ of the simulation time and a weaker bridging interaction between Fucp(1)-OH2 and Fucp(1)-OH3 (Fig. 7c) which is occupied for $28.4 \%$ of the simulation. The bridging events only take place for short periods of time yet Fucp(1)-O2 is involved in intramolecular water-bridging for $90 \%$ of the total simulation time.

\subsection{Comparison with previous studies}

\subsubsection{Comparison with NMR and in vacuo MD simulations.}

To allow analysis of the information available, it is important to note that the nomenclature used here is different to that used in other studies. We have used the notation $\mathrm{C} 1-\mathrm{O} 1-\mathrm{C}_{\mathrm{x}}-\mathrm{C}_{\mathrm{x}+1}$ as opposed to $\mathrm{C} 1-\mathrm{O} 1-\mathrm{C}_{\mathrm{x}}-\mathrm{C}_{\mathrm{x}-1}$ for the $\Psi$ torsion angles, which 
can be found in many literature sources. However, in order to make fair structural comparisons, the corresponding torsion angles were measured from the final structures of our MD simulations.

In comparison with previous NMR and in vacuo MD studies, our structures are in agreement in that the solvated $\mathrm{Le}^{\mathrm{x}}$ and $\mathrm{Le}^{\mathrm{y}}$ molecules are very rigid in terms of glycosidic torsion angle flexibility.[26-28] Our structures have also been shown to exhibit a variation of $\pm 20^{\circ}$ from the average torsion angle, with the glycosidic linkage unique to $\mathrm{Le}^{\mathrm{y}}$ being more flexible. NMR experiments of $\mathrm{Le}^{\mathrm{x}}$ carried out by Bush et. al. [27] show that the glycosidic torsion angles fluctuate by $\pm 10-15^{\circ}$ around the average structure, showing less flexibility than our simulations. The published in vacuo simulations however show a $\pm 10-20^{\circ}$ variation,[28] a value comparable to that reported here.

On comparing the structures from our solvated MD studies to the average structures from NMR and average structures from in vacuo MD studies, the torsion angles of our structures differ by up to $20^{\circ}$ for both $\mathrm{Le}^{\mathrm{x}}$ and $\mathrm{Le}^{\mathrm{y}}$.

\subsubsection{Comparison with crystal structures.}

The crystal structure of $\mathrm{Le}^{\mathrm{x}}$, and structures of $\mathrm{Le}^{\mathrm{x}}$ and $\mathrm{Le}^{\mathrm{y}}$ in complex with antibodies were taken from the literature as mentioned earlier, however in the case of the Le ${ }^{\mathrm{x}}$ dimer, the hydrogen atoms were added using the SYBYL7.0 program for visualisation purposes.

[Figure 8 here]

The hydrated crystal structure of the Le $\mathrm{x}^{\mathrm{x}}$ dimer (Fig. 8) shows that the conformation 
Finally, when comparing all of the available crystal structures together with the final structure produced from the $20 \mathrm{~ns}$ MD simulation, one can see that all the structures do not vary greatly, with the exception of the $\omega$ torsion angles (Fig. 9) and the torsion angle of the GlcNAc-O6 position.

[Figure 9 here]

Crystal structures of $\mathrm{Le}^{\mathrm{y}}$ complexed with hu3S193,[3] and CBR96,[30] show that the tetrasaccharide adopts a $\mathbf{g g}$ conformation, but again it is not known if this conformation is directed by the hydration of the tetrasaccharide or by the influence of the antibody upon complexation. In both of the crystal structures, the Galp(3) residue appears to be 
embedded in the protein surface. The oxygen atoms of the sugar molecules interact with more water molecules than mentioned here as can bee seen in the crystal structures, however, only the water molecules which correspond to some (of the many) possible interactions are considered.

When comparing all of the crystal structures mentioned above with the final conformation derived from the MD simulations, one can again see that there is no great variance (Fig. 10). As for $\mathrm{Le}^{\mathrm{x}}$, there is an inconsistency surrounding the "most occupied" torsion angle adopted for GlcNAc-O6 throughout the simulation, the gt rotomer, and that occupied when complexed with the protein, the gg rotomer.

One interesting point is that the final structure from the MD simulation shows that this $\omega$ torsion angle is in agreement with the other crystal structures, adopting a $g \boldsymbol{g}$ conformation.

[Figure 10 here]

\subsubsection{Bridging comparison with crystal structures.}

After studying the crystal structure of $\mathrm{Le}^{\mathrm{x}}$, one can see that there are many hydrogen bond interactions taking place and the molecule has a complex hydration sphere with a network of solute-solvent and solute-solute interactions. It appears that some of the interactions are bridging events, for example, between the heteroatoms at the positions GlcpNAc(2)-O4 and Galp(3)-O2. Another event can be observed between Gal $p(3)-\mathrm{O} 2$ and Galp(3)-O3. One can also see a more complex bridging event between GlcpNAc(2)-O6 and Galp(3)-O2 via 2 water molecules as shown in Figure 11 below. However, one would expect the more complex bridging events (involving more than one solvent molecule, Os1... Ow1... Ow2 ..Owx...Os2), to occur less frequently than a 
[Figure 11 here]

\subsubsection{Hydration features and comparison with crystal structures.}

By comparing the solute heteroatoms which exhibit bridging events using the $2 \mathrm{D}$ radial distribution functions in figure 7 and studying the crystal structures already mentioned (291-2G3-A, CBR96 and hu3s193) we are able to look for cases where a bridging event in the MD simulation could correspond to a bridging event in the crystal structure (either from a water molecule or a heteroatom from an amino acid residue).

On inspection of the $\mathrm{Le}^{\mathrm{x}}$ crystal structure, we are not able to see any water molecules which correspond to those found in the bridging events throughout the MD simulation. This does not necessarily indicate that they do not exist, or that the simulation is invalid, simply that they are not seen. For the crystal structure of Le ${ }^{\mathrm{x}}$ and 291-2G3-A bridging events between Galp(3)-O6 - Fucp(1)-O2 or Fucp(1)-O4 - Fucp(1)-O3 are not evident. 
However, a bridging event between Fucp(1)-O2 - Glc $p$ NAc(2)-CO via the alcohol group of a tyrosine residue (Tyr 32, distances of $4.163 \AA$ and $5.147 \AA$ from Fucp(1)-O2 and GlcpNAc(2)-CO respectively) can be seen. For the crystal structure of $\mathrm{Le}^{\mathrm{y}}$ and CBR96, only one of the bridging events shown in Figure 7 could occur. This is the event between Galp(3)-O6 - Fucp(1)-O2, again, via the alcohol group of a tyrosine residue (Tyr 35, distances of $2.684 \AA$ and $4.528 \AA$ from Galp(3)-O6 and Fucp(1)-O2 respectively. A distance of $2.501 \AA$ from $\operatorname{Fuc} p(1)-\mathrm{O} 3$ is also observed). The crystal structure of $\mathrm{Le}^{\mathrm{y}}$ complexed with hu3s193 seems to be more faithful to the events described by the MD simulation. Two water molecules from the crystal structure (molecule 72 distances of $2.758 \AA$ and $3.099 \AA$ from Fucp(4)-O3 and Fucp(4)-O2 respectively and molecule 278 distances of $4.332 \AA$ and $2.957 \AA$ from Fucp(4)-O3 and Fucp(4)-O2 respectively) are both in a position to be involved with bridging the heteroatoms Fucp(4)-O3 - Fucp(4)-O2. The carbonyl of a serine residue (Ser 104, distances of $3.110 \AA$ and $2.815 \AA$ from Fucp(1)-O4 and Fucp(1)-O3 respectively) can also be in a position to allow a bridging event to occur between Fucp(1)-O4 - Fucp(1)O3. Water molecules can also be seen to allow bridging interactions between the heteroatoms Fucp(1)-O2 - GlcpNAc(2)-CO (molecules 19 distances of $2.966 \AA$ and $4.019 \AA$ from Fucp(1)-O2 - GlcpNAc(2)-CO respectively) and Fucp(4)-O2 - Galp(3)$\mathrm{O} 3$ (molecule 72 distances of $2.957 \AA$ and $4.438 \AA$ from Fucp(4)-O2 and Galp-O3 respectively). An interesting point to note is the involvement of water molecule 72 in both the Fucp(4)-O3 - Fucp(4)-O2 and Fucp(4)-O2 - Galp-O3 events and could represent a four "bodied" system.

In the cases of the $\mathrm{Le}^{\mathrm{x}}, 291-2 \mathrm{G} 3-\mathrm{A}$ and CBR96 it is clear that the bridging events seen in the MD simulation are not seen. As previously mentioned, this could be because they are not seen in the crystal structures or they do not exist. If the latter is the case, this would imply that the water molecules of the free solute molecule would contribute to 


\section{Conclusions}

From our solution MD simulations of $\mathrm{Le}^{\mathrm{x}}$ and $\mathrm{Le}^{\mathrm{y}}$ we have shown that the solvated structures of the oligosaccharides remain rigid throughout the $20 \mathrm{~ns}$ simulation time and are comparable to previous NMR and in vacuo MD simulations.

This finding implies that these important oligosaccharides remain as targets for immunotherapeutic strategies for countering carcinoma as therapeutic agents would not have to account for large conformational changes expressed by the Lewis antigen targets and hence are able to be structurally specific. Structural comparisons have also been made to structures from four crystal structures currently available. Water molecule 
residence times and bridging events between oligosaccharide heteroatoms have also been investigated, and in particular bridging events have been found to occur between Fucp(1)-O2 - GlcpNAc(2)-CO of both $\mathrm{Le}^{\mathrm{x}}$ and $\mathrm{Le}^{\mathrm{y}}$ and Fucp(4)-O2 - Galp(3)-O3 of $\mathrm{Le}^{\mathrm{y}}$. By studying the crystal structures further, we have also been able to identify occasions where bridging water molecules may be present and thus potentially inducing structural changes in the solute allowing it to adopt a more active conformation. We have also identified occasions where bridging water molecules are not present in the crystal structures and have therefore been displaced from the solute thus contributing to the entropy of the interaction. Displacement of bridging water molecules by protein heteroatoms may also be seen.

Our work contributes to the understanding of carbohydrate interactions with water, which may be of importance for the biologically events taking place in the glycocalyx.

\section{Acknowledgements}

We wish to thank the GlycoGold research training network, a part of the $6^{\text {th }}$ research framework program of the European Union, contract number MRTN-CT-2004-005645 and to the Sialinsäuregesellschaft e. V., Kiel, for a travel stipend for A. Fuchs.

\section{References}

[1] J. Sakamoto, K. Furukawa, C. Cordon-Cardo, B.W. Yin, W.J. Rettig, H.F. Oettgen, L.J. Old and K.O. Lloyd, Expression of Lewisa, Lewisb, $X$, and Y blood group antigens in human colonic tumors and normal tissue and in human tumor-derived cell lines, Cancer. Res. 46 (1986), 1553-61.

[2] E. Yuriev, W. Farrugia, A.M. Scott and P.A. Ramsland, Three-dimensional structures of carbohydrate determinants of Lewis system antigens: implications for effective antibody targeting of cancer, Immunol. Cell. Biol. 83 (2005), 709-17.

[3] P.A. Ramsland, W. Farrugia, T.M. Bradford, M.P. Hogarth and A.M. Scott, Structural convergence of antibody binding of carbohydrate determinants in Lewis Y tumor antigens, J. Mol. Biol. 340 (2004), 809-18.

[4] A.D. McNaught, International Union of Pure and Applied Chemistry and International Union of Biochemistry and Molecular Biology. Joint Commission on Biochemical Nomenclature. Nomenclature of carbohydrates, Carbohydr. Res. 297 (1997), 1-92. 
[5] D.A. Case, T.A. Darden, T.E. Cheatham, III, C.L. Simmerling, J. Wang, R.E. Duke, R. Luo, K.M. Merz, B. Wang, D.A. Pearlman, M. Crowley, S. Brozell, V. Tsui, H. Gohlke, J. Mongan, V. Hornak, G. Cui, P. Beroza, C. Schafmeister, J.W. Caldwell, W.S. Ross and A. P.A. Kollman (2004), University of California, San Francisco.

[6] W.L. Jorgensen, J. Chandrasekhar, J.D. Madura, R.W. Impey and M.L. Klein, Comparison of simple potential functions for simulating liquid water, J. Chem. Phys. 79 (1983), 926-935.

[7] W.F.v. Gunsteren and H.J.C. Berendsen, Algorithms for macromolecular dynamics and constraint dynamics, Mol. Phys. 34 (1977), 1311-1327.

[8] S. Perez, N. Mouhous-Riou, N.E. Nifant'ev, Y.E. Tsvetkov, B. Bachet and A. Imberty, Crystal and molecular structure of a histo-blood group antigen involved in cell adhesion: the Lewis $x$ trisaccharide, Glycobiology 6 (1996), 537-42.

[9] W.F. Paul A. Ramsland, Tessa M. Bradford, P. Mark Hogarth and Andrew M. Scott, Structural Convergence of Antibody Binding of Carbohydrate Determinants in Lewis Y Tumor Antigens, J. Mol. Biol. 340 (2004), 809-818.

[10] Q. Pan, T. Klepach, I. Carmichael, M. Reed and A.S. Serianni, $4 J(C O C C H)$ and $4 J(C C C C H)$ as probes of exocyclic hydroxymethyl group conformation in saccharides, J. Org. Chem. 70 (2005), 7542-9.

[11] N.K. Devries and H.M. Buck, Different Rotamer Populations around the C-5-C-6 Bond for Alpha$D$-Galactopyranosides and Beta-D-Galactopyranosides through the Combined Interaction of the Gauche and Anomeric Effects - a 300-Mhz H-1-Nmr and Mndo Study, Carbohydr. Res. 165 (1987), 1-16.

[12] Y. Nishida, H. Ohrui and H. Meguro, H-1-Nmr Studies of (6r)-Deuterated and (6s)-Deuterated DHexoses - Assignment of the Preferred Rotamers About C5-C6 Bond of D-Glucose and DGalactose Derivatives in Solutions, Tetrahedron Lett. 25 (1984), 1575-1578.

[13] R.U. Lemieux, How water provides the impetus for molecular recognition in aqueous solution, Accounts. Chem. Res. 29 (1996), 373-380.

[14] X. Huang, J.J. Barchi, Jr., F.D. Lung, P.P. Roller, P.L. Nara, J. Muschik and R.R. Garrity, Glycosylation affects both the three-dimensional structure and antibody binding properties of the HIV-1IIIB GP120 peptide RP135, Biochemistry 36 (1997), 10846-56.

[15] W.G. Wu, L. Pasternack, D.H. Huang, K.M. Koeller, C.C. Lin, O. Seitz and C.H. Wong, Structural study on O-glycopeptides: Glycosylation-induced conformational changes of O-GlcNAc, OLacNAc, O-sialyl-LacNAc, and O-sialyl-lewis-X peptides of the mucin domain of MAdCAM-1, J. Am. Chem. Soc. 121 (1999), 2409-2417.

[16] D.M. Coltart, A.K. Royyuru, L.J. Williams, P.W. Glunz, D. Sames, S.D. Kuduk, J.B. Schwarz, X.T. Chen, S.J. Danishefsky and D.H. Live, Principles of mucin architecture: Structural studies on synthetic glycopeptides bearing clustered mono-, di-, tri-, and hexasaccharide glycodomains, J. Am. Chem. Soc. 124 (2002), 9833-9844.

[17] M.R. Pratt and C.R. Bertozzi, Synthetic glycopeptides and glycoproteins as tools for biology, Chem. Soc. Rev. 34 (2005), 58-68.

[18] F. Corzana, J.H. Busto, G. Jimenez-Oses, M. Garcia de Luis, J.L. Asensio, J. Jimenez-Barbero, J.M. Peregrina and A. Avenoza, Serine versus threonine glycosylation: the methyl group causes a drastic alteration on the carbohydrate orientation and on the surrounding water shell, J. Am. Chem. Soc. 129 (2007), 9458-67.

[19] F. Corzana, J.H. Busto, G. Jimenez-Oses, J.L. Asensio, J. Jimenez-Barbero, J.M. Peregrina and A. Avenoza, New insights into alpha-GalNAc-Ser motif: influence of hydrogen bonding versus solvent interactions on the preferred conformation, J. Am. Chem. Soc. 128 (2006), 14640-8.

[20] M.P. Allen and D.J. Tildesley, Computer Simulations of Liquids, Clarenden Press, Oxford, U.K., 1987.

[21] C.H.d.P. S Engelsen, Serge Perez, Molecular relaxation of sucrose in aqueous solutions: how a nanosecond molecular dynamics simulation helps to reconcile NMR data J. Phys. Chem. 99 (1995), 13334-13351.

[22] S.B. Engelsen and S. Perez, The hydration of sucrose, Carbohydr. Res. 292 (1996), 21-38.

[23] C. Andersson and S.B. Engelsen, The mean hydration of carbohydrates as studied by normalized two-dimensional radial pair distributions, J. Mol. Graph. Model. 17 (1999), 101-5, 131-3.

[24] S.B. Engelsen and S. Perez, Unique Similarity of the Asymmetric Trehalose Solid-State Hydration and the Diluted Aqueous-Solution Hydration, J. Phys. Chem. B 104 (2000), 9301-9311.

[25] S. Bekiroglu, L. Kenne and C. Sandstrom, NMR study on the hydroxy protons of the Lewis X and Lewis Y oligosaccharides, Carbohydr. Res. 339 (2004), 2465-8.

[26] H.F. Azurmendi, M. Martin-Pastor and C.A. Bush, Conformational studies of Lewis X and Lewis A trisaccharides using NMR residual dipolar couplings, Biopolymers 63 (2002), 89-98.

[27] K.E. Miller, C. Mukhopadhyay, P. Cagas and C.A. Bush, Solution structure of the Lewis $x$ oligosaccharide determined by NMR spectroscopy and molecular dynamics simulations, Biochemistry 31 (1992), 6703-9. 
[28] A. Imberty, E. Mikros, J. Koca, R. Mollicone, R. Oriol and S. Perez, Computer simulation of histoblood group oligosaccharides: energy maps of all constituting disaccharides and potential energy surfaces of 14 ABH and Lewis carbohydrate antigens, Glycoconj. J. 12 (1995), 331-49.

[29] A.M. van Roon, N.S. Pannu, J.P. de Vrind, G.A. van der Marel, J.H. van Boom, C.H. Hokke, A.M. Deelder and J.P. Abrahams, Structure of an anti-Lewis X Fab fragment in complex with its Lewis $X$ antigen, Structure 12 (2004), 1227-36.

[30] P.D. Jeffrey, J. Bajorath, C.Y. Chang, D. Yelton, I. Hellstrom, K.E. Hellstrom and S. Sheriff, The xray structure of an anti-tumour antibody in complex with antigen, Nat. Struct. Biol. 2 (1995), 466-71.

Figure 1. Structure of Lewis $x\left(\operatorname{Le}^{\mathrm{x}}\right)$ trisaccharide (1a) and Lewis $y\left(\mathrm{Le}^{\mathrm{y}}\right)$ tetrasaccharide (1b).

Figure 2. Potential energy surfaces for the glycosidic linkages of $\operatorname{Le}^{\mathrm{x}} \operatorname{Fucp}(1)-\operatorname{Glc} p N A c(2)$ (a), GlcpNAc(2)-Galp(3) (b) and Le ${ }^{y}$ Fucp(1)-GlcpNAc(2) (c), GlcpNAc(2)-Galp(3) (d), Galp(3)-Fucp(4) (e).

Figure 3. variation with time for the glycosidic linkages of $\operatorname{Le}^{\mathrm{x}}$ (left) and $\mathrm{Le}^{\mathrm{y}}$ (right). (a) $\Phi$ Fucp(1)GlcpNAc(2), (b) $\Psi$ Fucp(1)-GlcpNAc(2), (c) $\Phi$ GlcpNAc(2)-Galp(3), (d) $\Psi$ GlcpNAc(2)-Galp(3), (e) $\Phi$ Galp(3)-Fucp(4), (f) $\Psi$ Galp(3)-Fucp(4).

Figure 4. Histograms of the distribution of the population of torsion angles occupied for the glycosidic linkage of O5-C5-C6-O6, $\omega$, of the Galp(3) residue of $\mathrm{Le}^{\mathrm{x}}$ (a) and $\mathrm{Le}^{\mathrm{y}}(\mathrm{b})$.

Figure 5. Rotational (a) and translational (b) diffusion coefficients for Le $e^{\mathrm{x}}$ and Le $\mathrm{e}^{\mathrm{y}}$.

Figure 6. 1D Radial distribution functions (rdf) for selected oxygen atoms of Le $e^{\mathrm{x}}$ (a) and $\operatorname{Le}^{\mathrm{y}}$ (b).

Figure 7. 2D radial distribution functions for the selected hetero atoms (a) Galp(3)-O2 and GlcpNAc(2)-O6 (b) Galp(3)-O6 and Fucp(1)-O2 (c) Fucp(4)-O2 and Fucp(4)-O3 (d) Fucp(1)-O3 and Fucp(1)-O4 (e) Fucp(1)-O2 and GlcNAcp(2)-CO of Le ${ }^{x}$ and Le $\mathrm{L}^{\mathrm{y}}$ and (f) Fucp(4)-O2 and Galp(3)-O3 of $\mathbf{L} \mathbf{e}^{\mathrm{y}}$.

Figure 8. Crystal structure of the hydrated $L e^{x}$ dimer.

Figure 9. Comparison of the final structure from the $20 \mathrm{~ns} \mathrm{Le}^{\mathrm{x}} \mathrm{MD}$ simulation (carbons coloured in dark blue) with the $\mathrm{Le}^{\mathrm{x}}$ crystal structure (carbons coloured in green), [8] and the structure extracted from the 291-2G3-A complex (carbons coloured in light blue). [29]

Figure 10. Comparison of the final structure from the $20 \mathrm{~ns} \mathrm{Le}^{\mathrm{x}} \mathrm{MD}$ simulation (carbons coloured in dark blue) with the complexes hu3S193 (carbons coloured in light blue) and CBR96 (carbons coloured orange).

Figure 11. Complex bridging event seen in the crystal structure of Lex. The hydrogen bonds are represented by the black dashed lines.

Table 1. Maximum and average residence times for water molecules approaching within $3.5 \AA \AA$ of the oligosaccharide heteroatom listed. 


\section{Page 25 of 36}

1

2

3

4

5

6

7

8

9

10

11

12

13

14

15

16

17

18

19

20

21

22

23

24

25

26

27

28

29

30

31

32

33

34

35

36

37

38

39

40

41

42

43

44

45

46

47

48

49

50

51

52

53

54

55

56

57

58

59

60

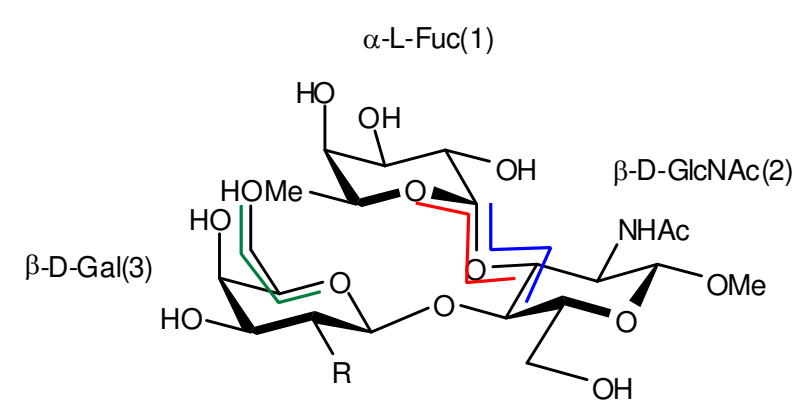

1a $\quad \mathrm{Le}^{\mathrm{x}} \quad \mathrm{R}=\mathrm{OH}$

1b Le $\quad$ L $\quad R=$

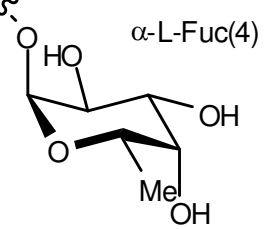

Lewis $X$ trisaccharide (Le ${ }^{\mathrm{x}}$ [ $[\beta-\mathrm{D}-\mathrm{Gal} p-(1-4)[\alpha-\mathrm{L}-\mathrm{Fucp}-(1-3)]-\beta-\mathrm{D}-\mathrm{Gl} c p N A \mathrm{Ac}]$

Lewis $Y$ trisaccharide (Le $\left.{ }^{y}\right)[\alpha-L-F u c p-(1-2)-\beta$-D-Galp-(1-4)[ $\alpha$-L-Fuc $p$-(1-3)]- $\beta$-D-GlcpNAc]
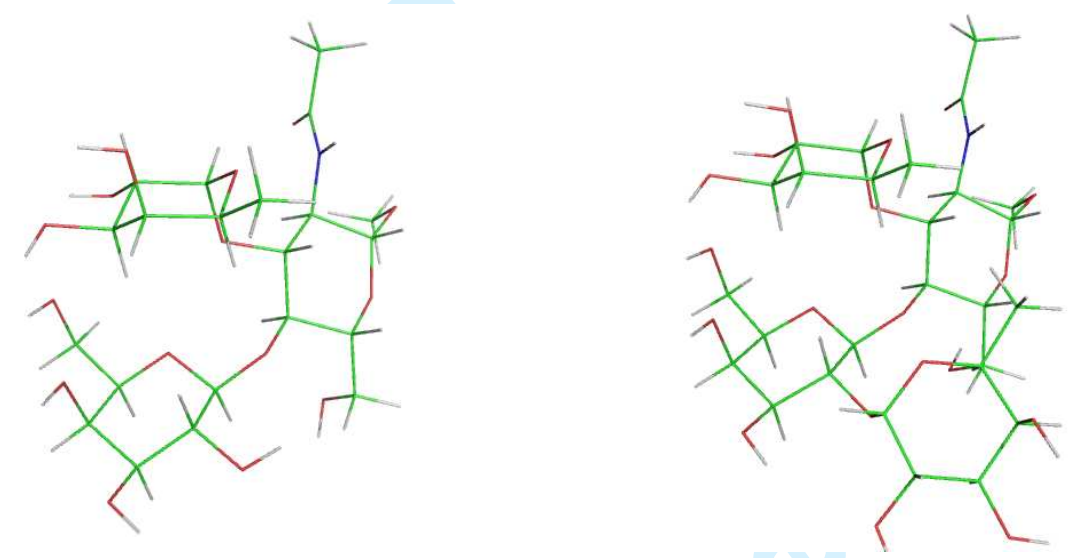

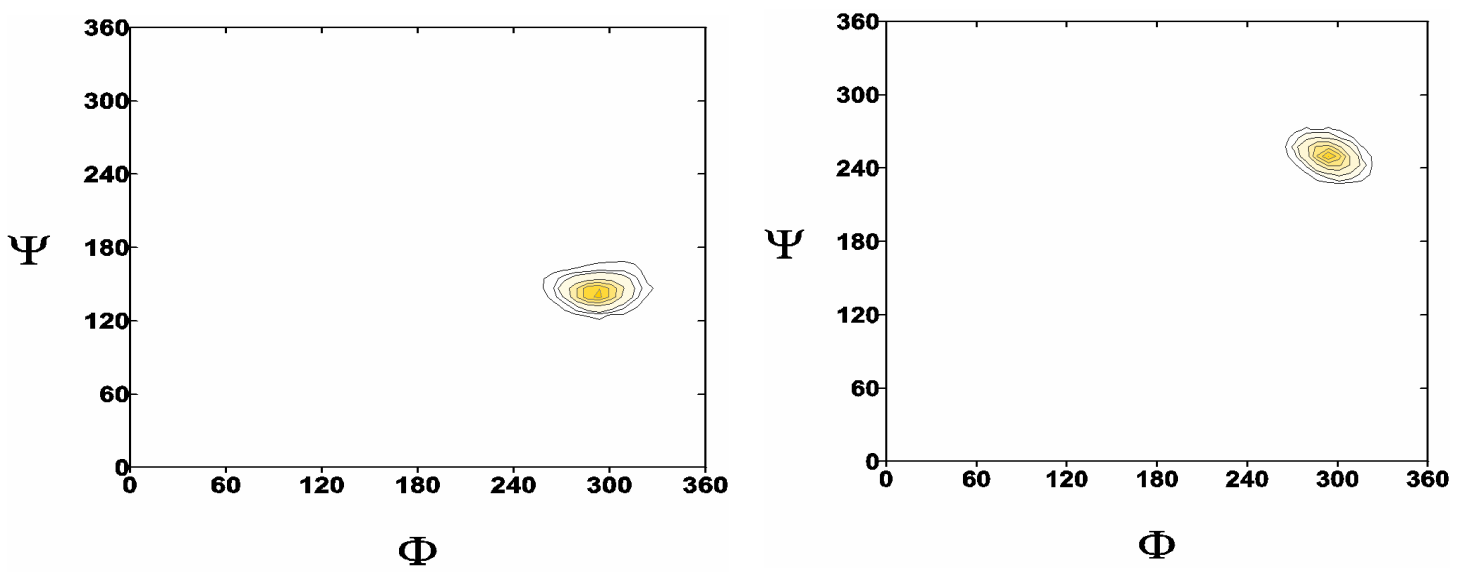

$\Phi$

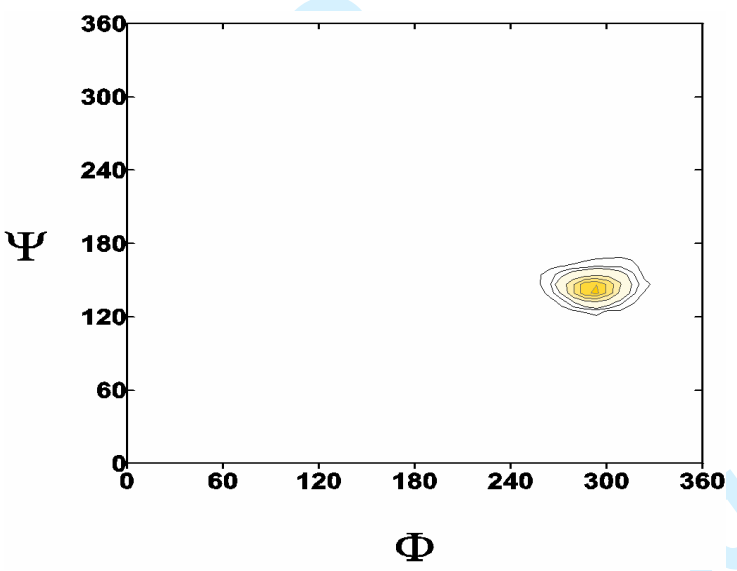

b

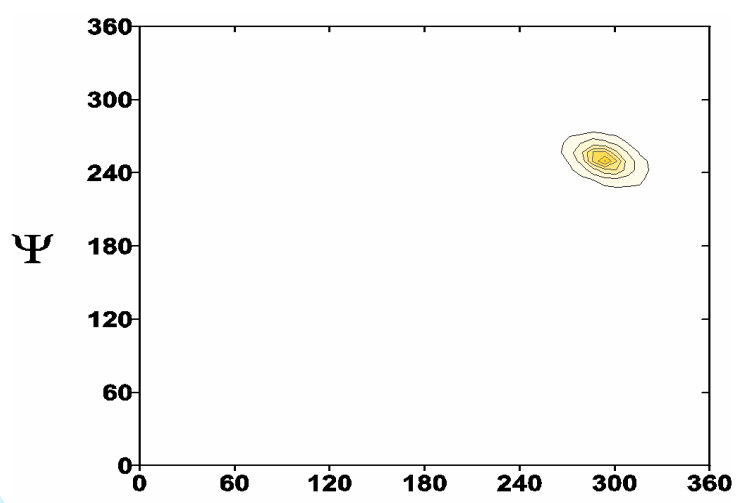

$\Phi$

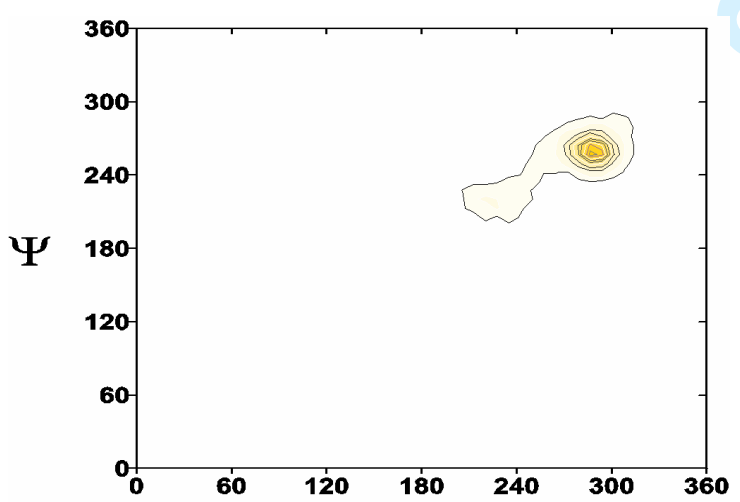

$\Phi$

e

48

49

50

51

52

53

54

55

56

57

58

59 


\section{Page 27 of 36}

1
2
3
4
5
6
7
8
9
10
11
12
13
14
15
16
17
18
19
20
21
22
23
24
25
26
27
28
29
30
31
32
33
34
35
36
37
38
39
40
41
42
43
44
45
46
47
48
49
50
51
52
53
54
55
56
57
58
59
60
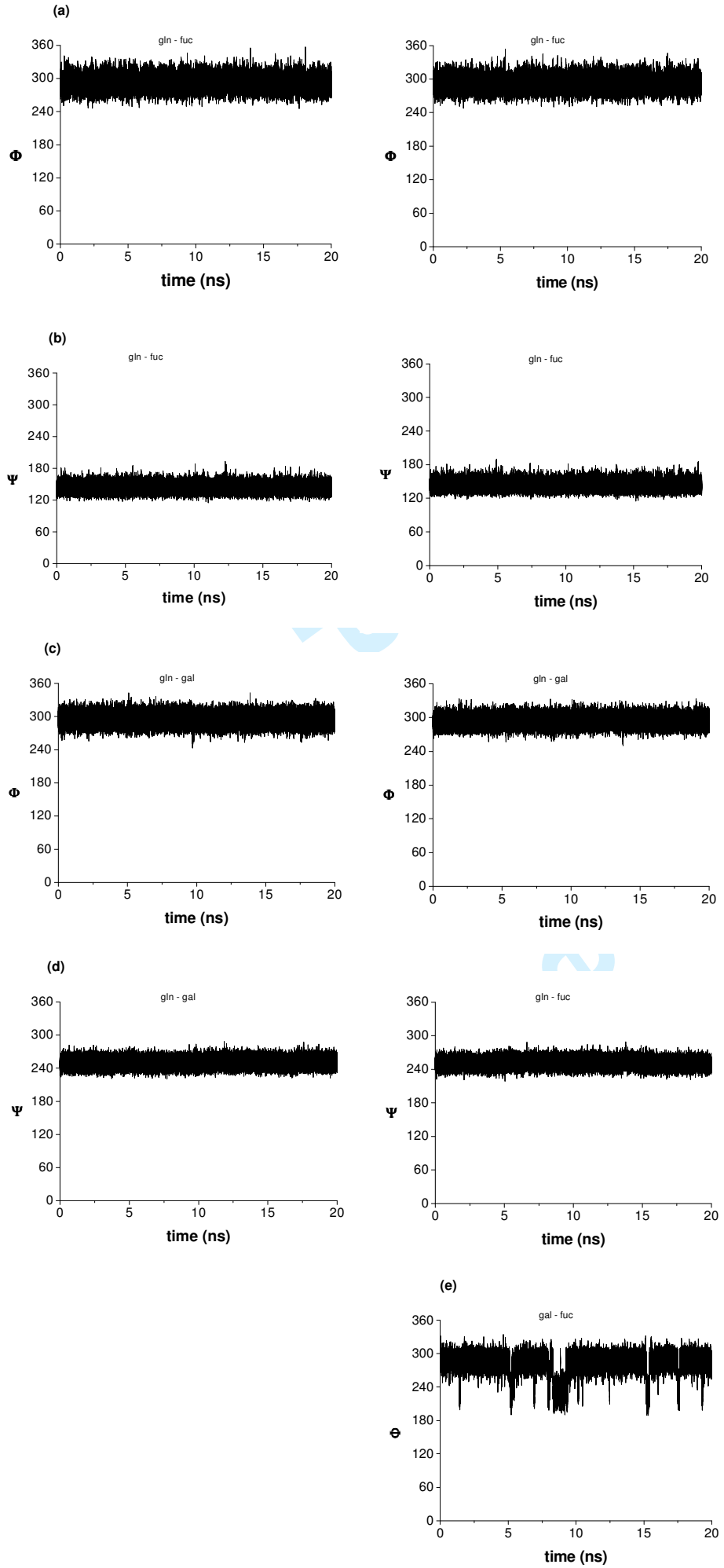

http://mc.manuscriptcentral.com/tandf/jenmol 


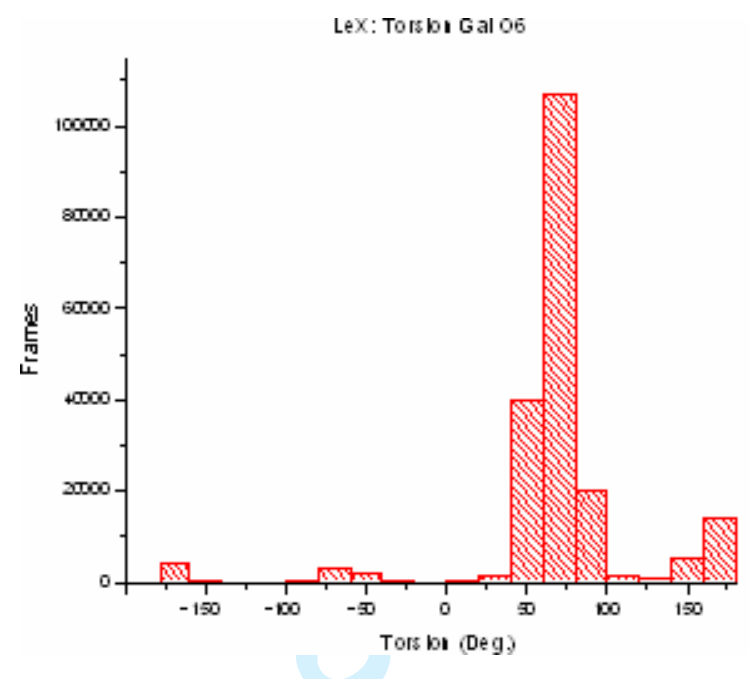

(a)

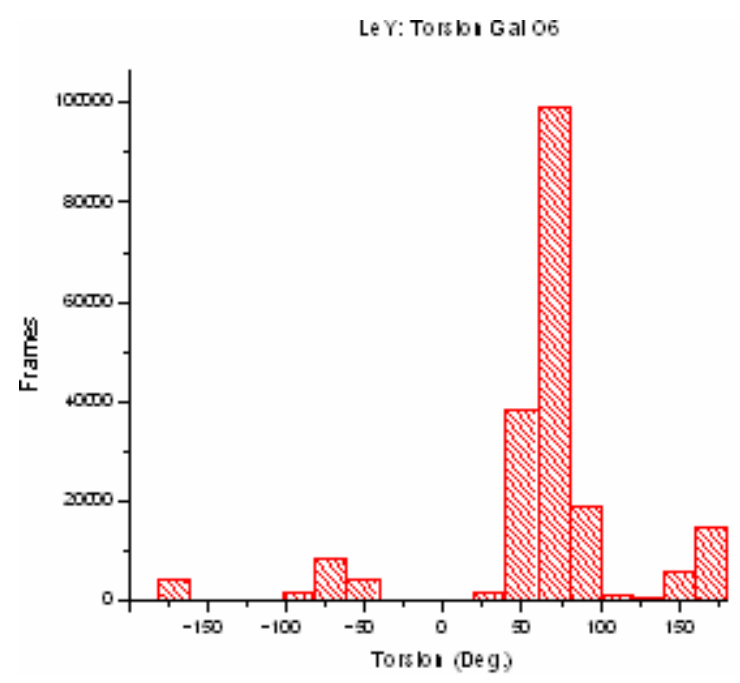

(b) 


\section{Page 29 of 36}

1

2

3

4

5

6

7

9

10

11

12

13

14

15

16

17

18

19

20

21

22

23

24

25

26

27

28

29

30

31

32

33

34

35

36

37

38

39

40

41

42

43

44

45

46

47

48

49

50

51

52

53

54

55

56

57

58

59

60

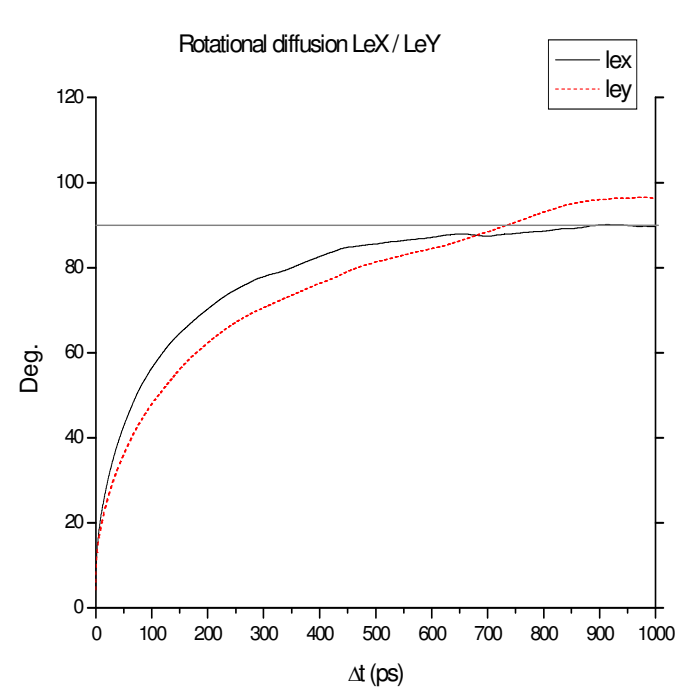

(a)

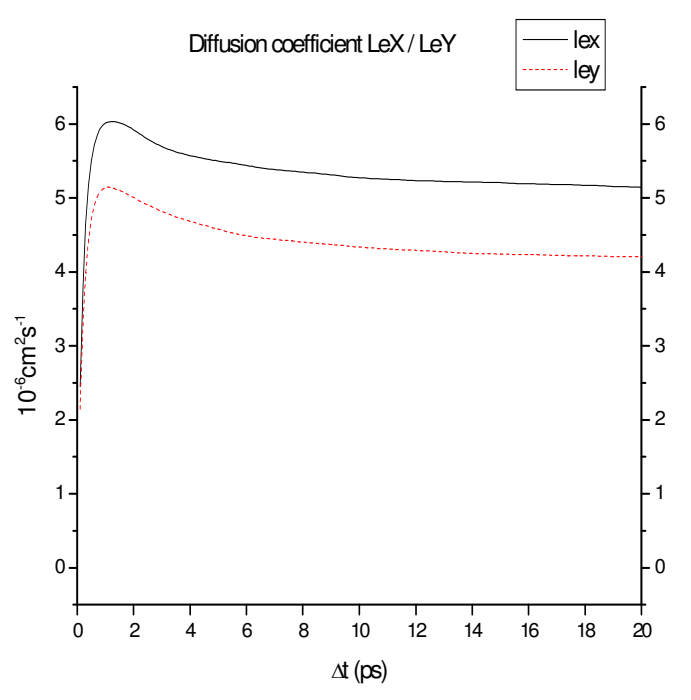

(b) 


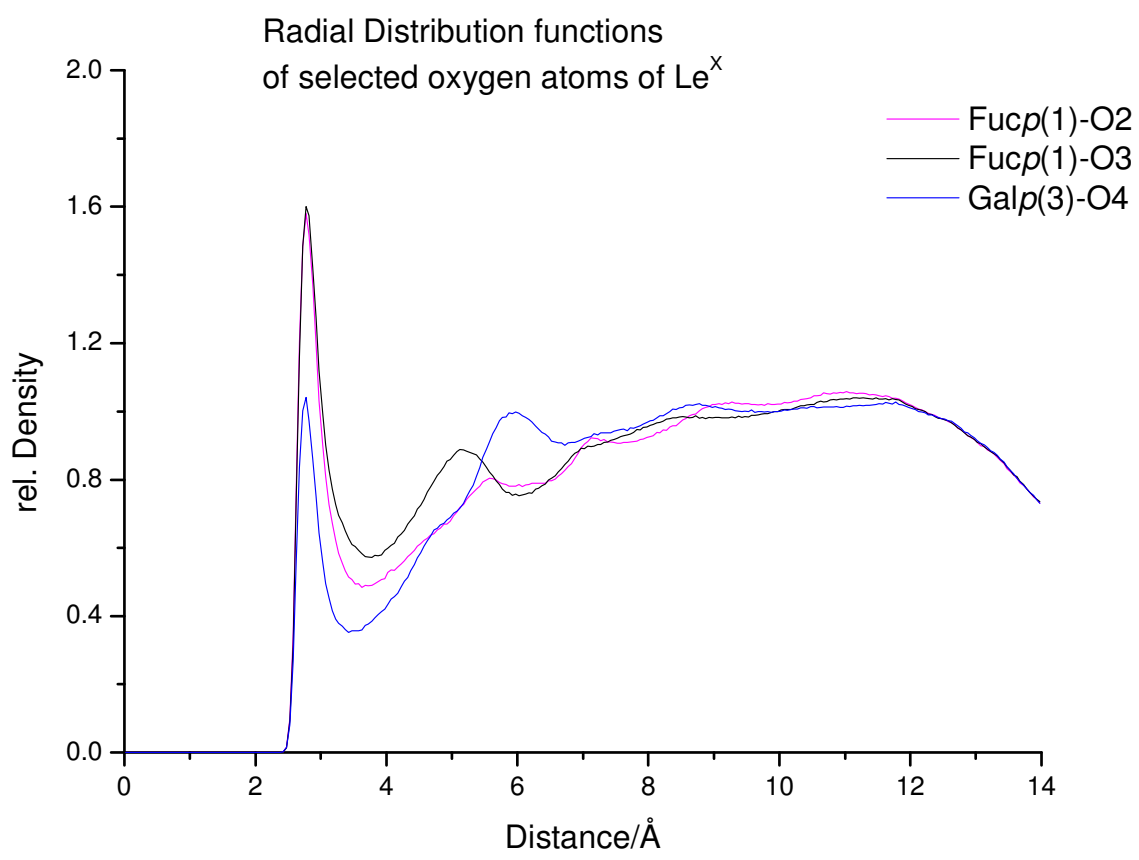

a

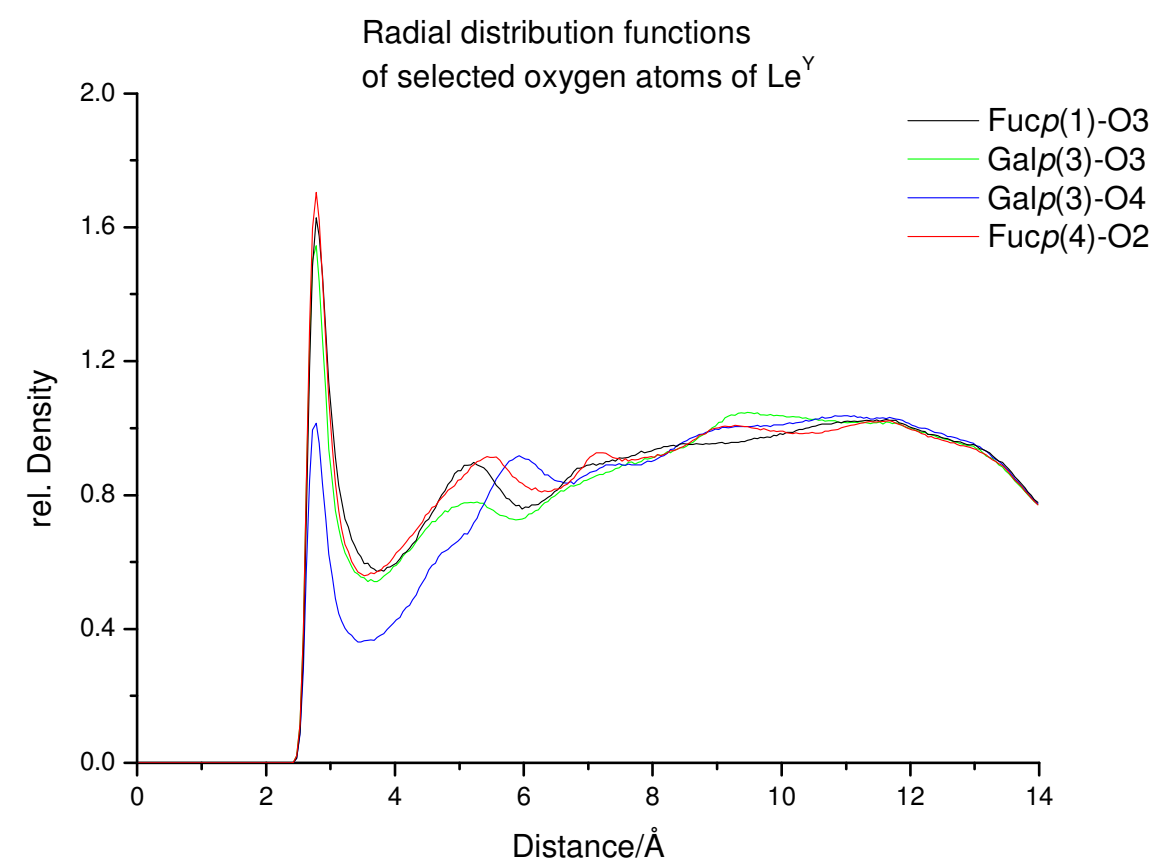

b 


\section{Page 31 of 36}

1

2

3

4

5

6

8

9

10

11

12

13

14

15

16

17

18

19

20

21

22

23

24

25

26

27

28

29

30

31

32

33

34

35

36

37

38

39

40

41

42

43

44

45

46

47

48

49

50

51

52

53

54

55

56

57

58

59

60

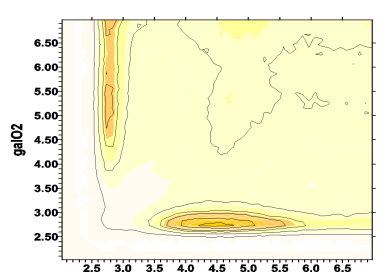

ginos
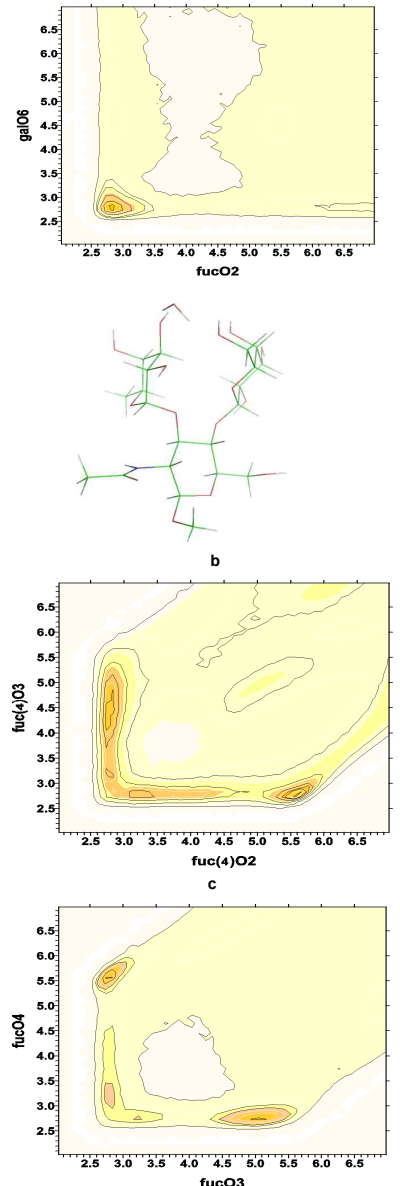

d
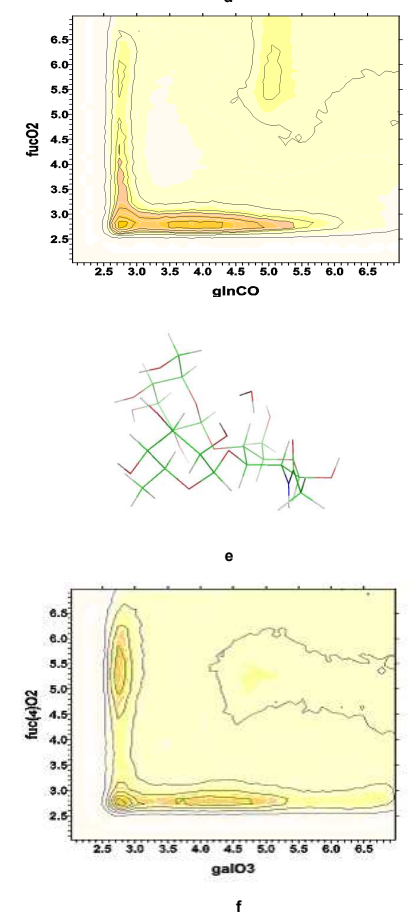


http://mc.manuscriptcentral.com/tandf/jenmol 


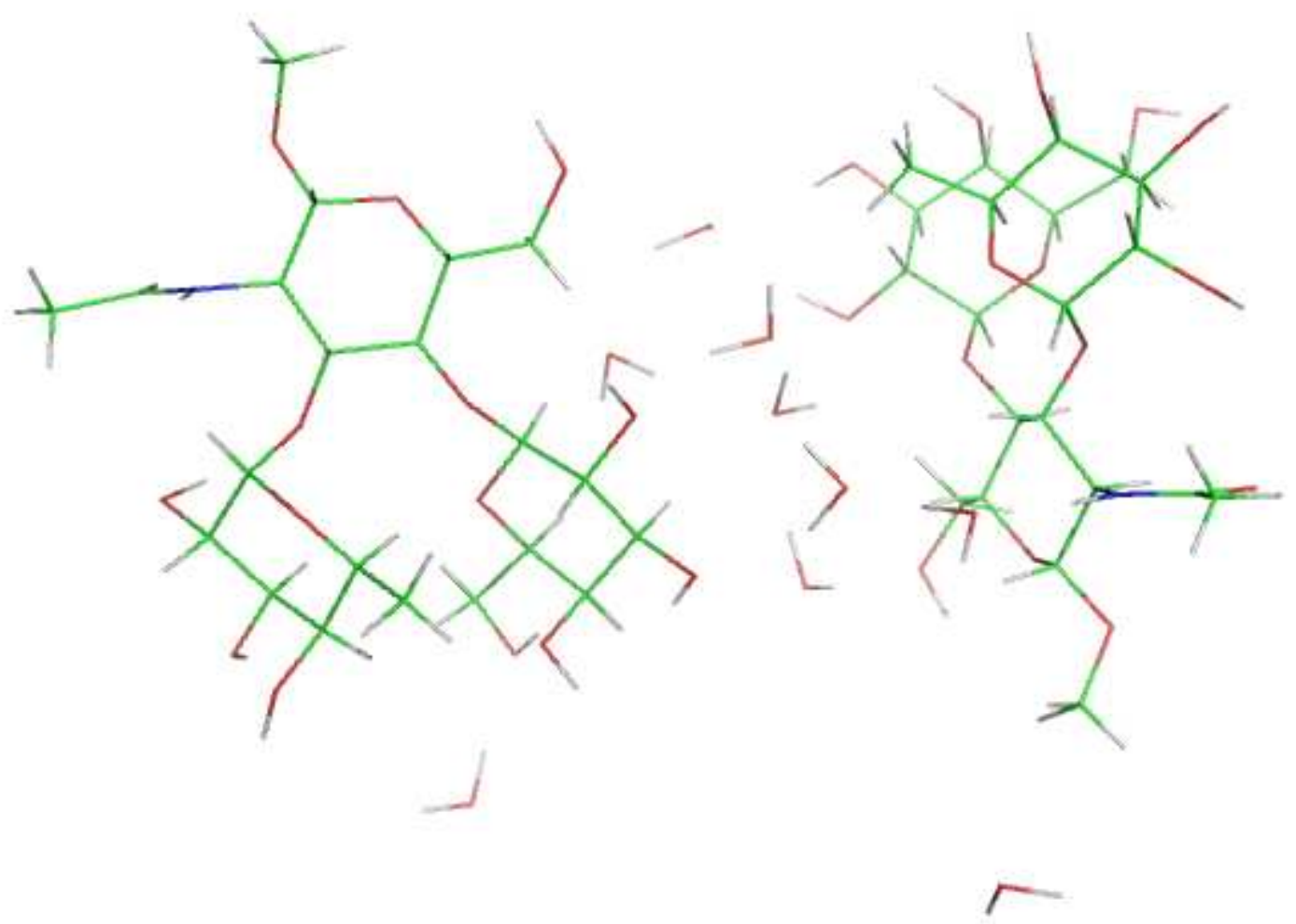




\section{Page 33 of 36}

1
2
3
4
5
6
7
8
9
10
11
12
13
14
15
16
17
18
19
20
21
22
23
24
25
26
27
28
29
30
31
32
33
34
35
36
37
38
39
40
41
42
43
44
45
46
47
48
49
50
51
52
53
54
55
56
57
58
59
60



http://mc.manuscriptcentral.com/tandf/jenmol 
Page 34 of 36

1
2
3
4
5
6
7
8
9
10
11
12
13
14
15
16
17
18
19
20
21
22
23
24
25
26
27
28
29
30
31
32
33
34
35
36
37
38
39
40
41
42
43
44
45
46
47
48
49
50
51
52
53
54
55
56
57
58
59
60

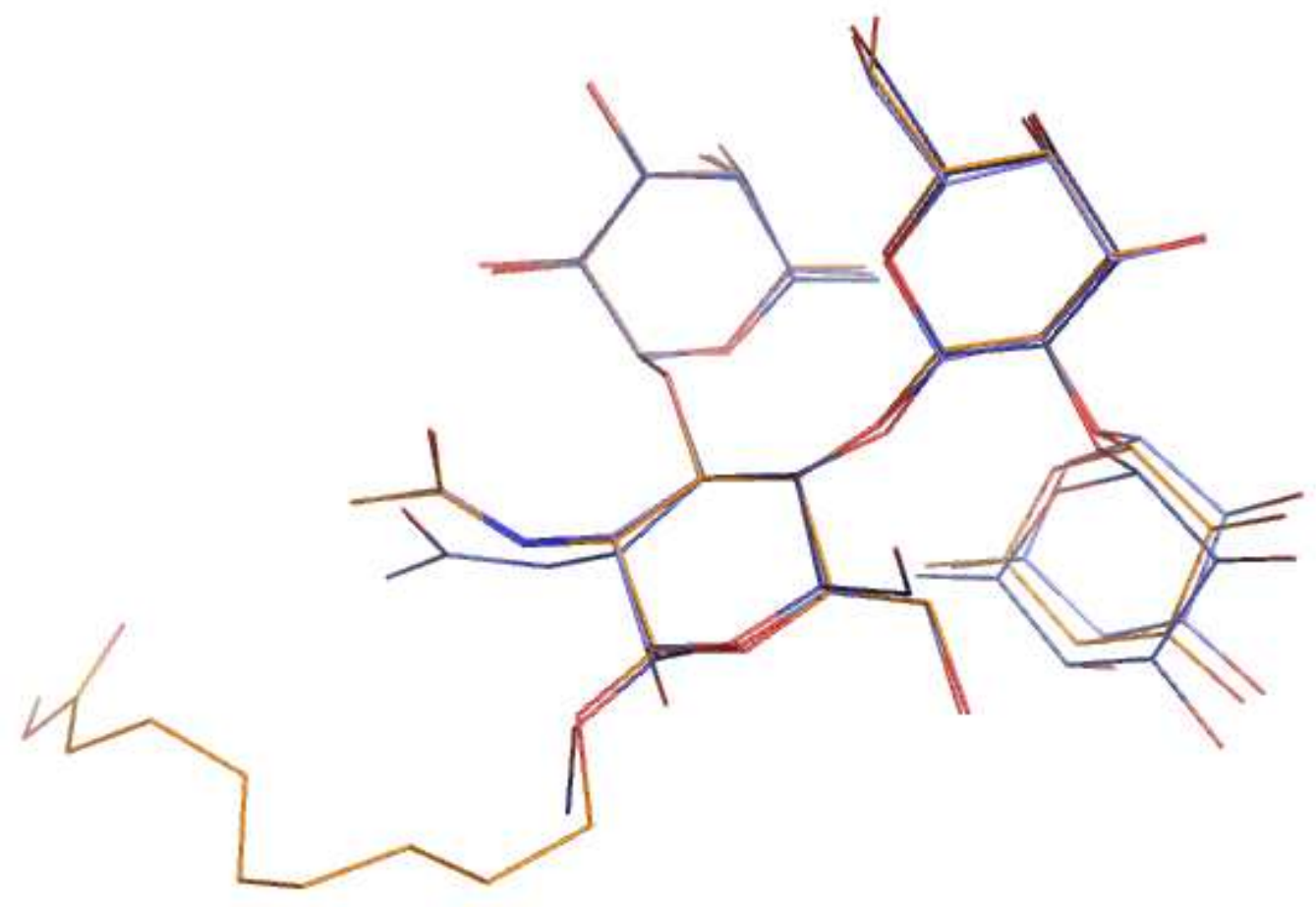

http://mc.manuscriptcentral.com/tandf/jenmol 


\section{Page 35 of 36}

1
2
3
4
5
6
7
8
9
10
11
12
13
14
15
16
17
18
19
20
21
22
23
24
25
26
27
28
29
30
31
32
33
34
35
36
37
38
39
40
41
42
43
44
45
46
47
48
49
50
51
52
53
54
55
56
57
58
59
60

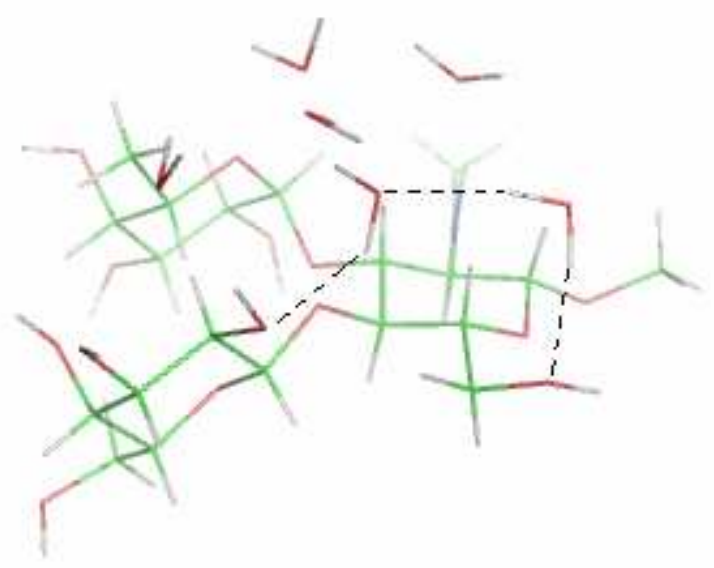

19

(20

22

23

26

27

28

30

31

32

33 


\begin{tabular}{|c|c|c|c|c|c|c|}
\hline \multirow[b]{2}{*}{ atom } & \multicolumn{3}{|c|}{$\mathrm{Le}^{\mathrm{x}}$} & \multicolumn{3}{|c|}{$\mathrm{Le}^{\mathrm{y}}$} \\
\hline & $\mathrm{T}_{\max } / \mathrm{ps}$ & $\mathrm{T}_{\mathrm{av}} / \mathrm{ps}$ & significance & $\mathrm{T}_{\max } / \mathrm{ps}$ & $\mathrm{t}_{\mathrm{av}} / \mathrm{ps}$ & Significance \\
\hline Fucp(1)-O2 & 62.4 & 2.74 & 99 & 42.4 & 2.65 & 99 \\
\hline $\mathrm{O} 3$ & 27.7 & 2.23 & 99 & 33.6 & 2.26 & 99 \\
\hline $\mathrm{O} 4$ & 45.0 & 3.12 & 99 & 38.8 & 3.13 & 99 \\
\hline $\mathrm{O} 5$ & 6.1 & 0.42 & 98 & 6.2 & 0.41 & 98 \\
\hline GlcNAcp(2)- & 16.3 & 0.86 & 95 & 13.7 & 0.86 & 95 \\
\hline $\mathrm{O} 1$ & & & & & & \\
\hline $\mathrm{O} 3$ & 18.4 & 0.87 & 74 & 15.1 & 0.85 & 74 \\
\hline $\mathrm{O} 4$ & 7.6 & 0.51 & 61 & 3.1 & 0.27 & 1 \\
\hline O5 & 12.1 & 0.64 & 89 & 11.5 & 0.65 & 89 \\
\hline O6 & 25.9 & 2.28 & 99 & 35.8 & 2.67 & 99 \\
\hline $\mathrm{CO}$ & 22.2 & 2.15 & 99 & 23.4 & 2.09 & 99 \\
\hline $\mathrm{N}$ & 17.4 & 1.20 & 92 & 26.8 & 1.21 & 92 \\
\hline Galp(3)-O2 & 61.0 & 3.19 & 99 & 7.7 & 0.44 & 56 \\
\hline $\mathrm{O} 3$ & 30.9 & 2.40 & 99 & 28.1 & 2.72 & 99 \\
\hline $\mathrm{O} 4$ & 40.9 & 2.31 & 98 & 45.0 & 2.35 & 98 \\
\hline $\mathrm{O} 5$ & 2.9 & 0.23 & 35 & 3.90 & 0.24 & 36 \\
\hline O6 & 31.8 & 2.45 & 99 & 34.7 & 2.40 & 99 \\
\hline Fucp(4)-O2 & & & & 45.8 & 2.66 & 99 \\
\hline $\mathrm{O} 3$ & & & & 21.9 & 2.05 & 99 \\
\hline $\mathrm{O} 4$ & & & & 46.4 & 2.82 & 99 \\
\hline $\mathrm{O} 5$ & & & & 23.0 & 1.18 & 88 \\
\hline
\end{tabular}

